\section{A Study of Normal Human Cerebrospinal Fluid by the Immuno-Electrophoretic Method}

THE immuno-electrophoretic method ${ }^{1}$ allows the definition of the constituents of a mixture of antigenic substances by means of their relative electrophoretic mobilities, and their enumeration, by specific precipitation, by means of a homologous immune serum. The study of normal human serum by this method has allowed the enumeration of at least sixţen different constituents ${ }^{2}$.

We have studied, by the same method, normal cerebrospinal fluid concentrated by ultra-filtration ${ }^{3}$, by using horse immune serum (No. 31) anti-normal human serum, which has been used in the study of human serum. In a parallel manner we have submitted the same samples of cerebrospinal fluid to ordinary electrophoresis on agar under the same conditions as used for immuno-electrophoretic analysis. The agar gels were then dried, and the protein and lipid constituents were stained in situ by methods similar to those used previously ${ }^{4}$.

The plain electrophoretic analysis in a gelified medium shows (Fig. 1) that the cerebrospinal fluid contains : a substance which migrates more quickly than albumin; much albumin ; a small amount of $\alpha$-globulins ; $\beta_{1^{-}}$and $\beta_{2}$-globulins and a small amount of $\gamma$-globulins.

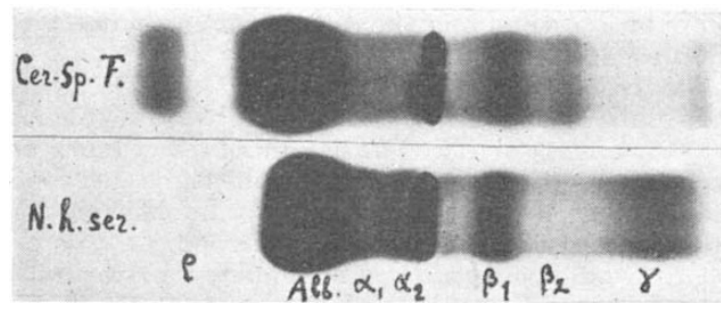

Fig. 1

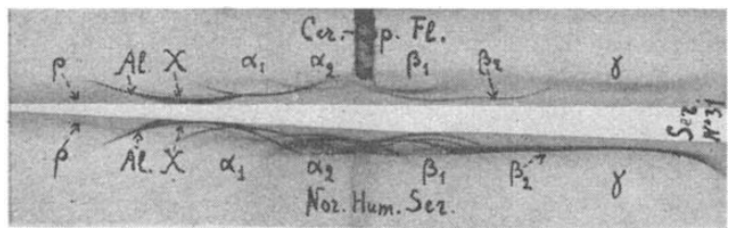

Fig. 2

The immuno-electrophoretic analysis (Fig. 2. allows us to distinguish the following : a constituent which migrates more rapidly than albumin and which would seem identical with the p-constituent of blood serum ${ }^{2}$; serum albumin; a constituent having the same mobility as albumin which is probably identical with the $\chi$-constituent in blood serum ${ }^{2}$; one or probably two $\alpha_{1}$-globulins ; three $\alpha_{2}$-globulins ; at least one $\beta_{1}$-globulin; a single antigenic constituent having, however, two different migrationrates. This latter corresponds to the $\beta_{2}$-globulins and the small amount of $\gamma$-globulins which corresponds to the slow $\gamma$-globulins of the serum.

As we have used a total immuno-serum human antiserum, we could only distinguish in the cerebrospinal fluid constituents existing in the serum; there may also be other constituents specific to the cerebrospinal fluid. Our results do, however, demonstrate that the distribution of protein constituents in the cerebro-spinal fluid is not the same as in the serum itself.

Detailed results will be published in the Bull. Soc. Chim. Biol.
K. Gavrilesco
J. URIEL
J. Courcon
J. LEWIN
P. Hinhion
P. GRABAR

Service de Chimie Microbienne, Institut Pasteur, Paris 15.

${ }^{1}$ Grabar, P., and Williams, C. A., Biochim. Biophys. Acta, 10, 193 (1953); 17, 676 (1955).

2 Williams, C. A., and Grabar, P., J. Immunol., 74, 158 (1955).

3.Baudouin, A., Lewin, J., and Million, P., C.R. Soc. Biol., Paris, 147, 1036 (1953).

4 Uriel, J., and Scheidegger, J. J., Bull. Soc. Chim. Biol., 37, 165 (1953). Uriel, J. and Grabar, $\dot{P}$. (in the press).

${ }^{5}$ Lewin, J., C.R. Soc. Biol., Paris (in the press).

\section{Effect of Heat Stress on Serial Reaction Time in Man.}

EXPERIMENTAL studies of the effects of ambient temperatures on simple reaction time have suggested that there may be a negative correlation between simple reaction time and temperature, but results appeared to be rather inconclusive. In fact Teichner ${ }^{1}$, in a review of studies of simple reaction time, concludes that ambient temperatures between $-50^{\circ}$ and $117^{\circ} \mathrm{F}$. have little or no effect on either simple reaction time or more complex reaction times.

In a series of experiments on the effects of ambient temperatures ranging from $90^{\circ}$ to $104^{\circ} \mathrm{F}$. (90-95 per cent saturation), we had occasion to study the effects of such temperatures on both simple reaction time and serial reaction time. In serial reaction time the signals are presented to the subject continuously with irregular occurrence of the signals to action, and without the warning signals customary in experiments on simple reaction time. It may reasonably be argued that serial reaction time is a more realistic measure than simple reaction time, since in the skills of everyday life we are seldom given warning of the arrival of a significant stimulus.

The apparatus used in these experiments was the Cambridge visual vigilance test ${ }^{2}$, coupled to a photoelectric cell and a pulse-height discriminator operating a clock-starting relay. This gave a very accurate measure of reaction time.

Seven subjects were tested over a period of five days, serial reaction time being measured before entry into the heat chamber, after one hour exposure to the above range of temperatures, and after two hours exposure. For each measurement of reaction time the subject was presented with a large number of stimuli in a short time (forty stimuli in $5 \mathrm{~min}$. in random order). The mean serial reaction times are shown in Table 1. It will be seen that the rise in reaction time under heat stress is small but statistirally significant.

\begin{tabular}{|l|c|c|}
\hline & $\begin{array}{c}\text { Mean serial } \\
\text { reaction time (sec.) }\end{array}$ & $P$ \\
\hline Control & 0.247 & \\
First hour & 0.256 & \\
Second hour & 0.267 & $0.05^{*}$ \\
Control v. first hour & & $0.01 \dagger$ \\
Control v. second hour & & $0.05^{*}$ \\
First v. second hour & & \\
\hline
\end{tabular}

* Signiflcant.

† Highly signifleant. 